\title{
Root Reimplantation with Aortic Arch Replacement and Frozen Elephant Trunk in Acute Aortic Dissection
}

\author{
Kwangjo Cho* and Sungshil Yoon \\ Department of Thoracic and Cardiovascular Surgery, Dong-A University, South Korea
}

Submission: May 21, 2018; Published: July 13, 2018

*Corresponding author: Kwangjo Cho, Department of Thoracic and Cardiovascular Surgery, Dong-A University, 3-1 Dongdeashin Dong, Suh Gu, Pusan, South Korea, Tel: 051-240-2879; Email: kwangjocho@gmail.com

\begin{abstract}
Aortic root reimplantation is one of good options for aortic valve preservation in aortic root diseases. In young patients with long life expectancy this manuevor can avoid a life long anticoagulation. We experienced two cases of aortic root reimplantation with total arch replacement and frozen elephant trunk in acute aortic dissection and the result was acceptable.
\end{abstract}

Keywords: Aortic root reimplantation; Aortic dissection

\section{Case Presentation}

\section{Case 1}

A 50-years-old woman was admitted under the diagnosis of acute type A aortic dissection (Figure $1 \mathrm{~A} \& 1 \mathrm{~B}$ ). An emergency operation was performed through median sternotomy and antegrade cerebral perfusion with moderated hypothermia. During the operation we found that the ascening aorta was dilated and the intimal were teared in mid ascending aorta and the dissection was extended throughout the whole aorta. The aortic root was dilated especially in the noncoronary sinus (Figure 1C) but the aortic leaflet was well preserved. We connected arterial line via $8 \mathrm{~mm}$ graft anastomosed into the right subclavian artery through a seperated subclavian incision, and venous cannulation was performed with a single venous cannule into the right atrium. During establishing the moderate hypothermia, the ascending aorta was clamped, and cardia arrest was induced with retrograde cardioplegic infusion. The aortic root was dissected down to the level of the aortic anulus and the both coronary orifice were deteched from the sinus and the aortic anulus was trimed as a bottom shape after removal of all sinus wall.

Eleven horizontal mattris sutures of pledgetted 2-0 Tycron were passed from the inside to the outside of the subanular left ventricular outflow tract through a single horizontal plane. The sutures were passed from the inside to the outside of the end of a $30 \mathrm{~mm}$ Dacron tube graft. After the all remnant anular tissue containing three commissures were placed within the tube graft, all sutures were tied on the outside. The three commissures were suspended and fixed within the graft with simple running suture of
4-0 polypropylene. The both coronary artery was reimplanted into the corresponding neosinuses with 5-0 polypropylene sutures. Three plication sutures were placed above the commissures to create the neosinotubular junction. When the body temperature reached 28 degree Celcius, we clamped the inominate artery and the aortic arch were opened and another canule was inserted into the left carotid artery to establish the bilateral antegrade cerebral perfusion. After transection of the descending aorta a $28 \mathrm{~mm} \times 15 \mathrm{~cm}$ Valiant Captiva was placed into the true lumen of the dissected descending aorta directly through the opened aorta with the protection of a guide wire and deployed. A $28 \mathrm{~mm}$ four sided arch graft was anastomosed into stented descending aorta with pledgetted outer Teflon felt strip and 3-0 polypropylend suture and systemic perfusion through side branch and rewarming was started. After the proximal intergraft end to end anastomosis was completed aortic clamp was released and coronary perfusion was restarted. Three arch branches were connected into the corresponding side branches of the arch graft and the subclavian artery perfusions were disconnected sequentially.

After rewarming and hemodynamic stability was reestablished, the cardiopulumonary bypass was weanined without difficulty and the cannules were removed. Hemostasis was completed consequently and the surgical wound was closed with remaining two chest tubes. The total operation time was 6 hours and 50 minutes, and the total bypass time was 4 hours and 52 minutes, and the coronary ischemic time was 3 hours and 13 minutes. After the operation the ventilator support period was 15 hours and the total ICU stay period was 8 days. During postoperative period 
the patient developed pericardial effusion which was subsided with pericardiocentesis and AV block without clinical symptoms, which needed some period for recovery. The patient discharged on 30 day after the surgery because of the AV block and followed up at our out patient clinic. Following study with CT angiogram and echocardiogram, there were no aortic regurgetation and only distal abdominal aorta remained dissection without dilatation (Figure 1D).

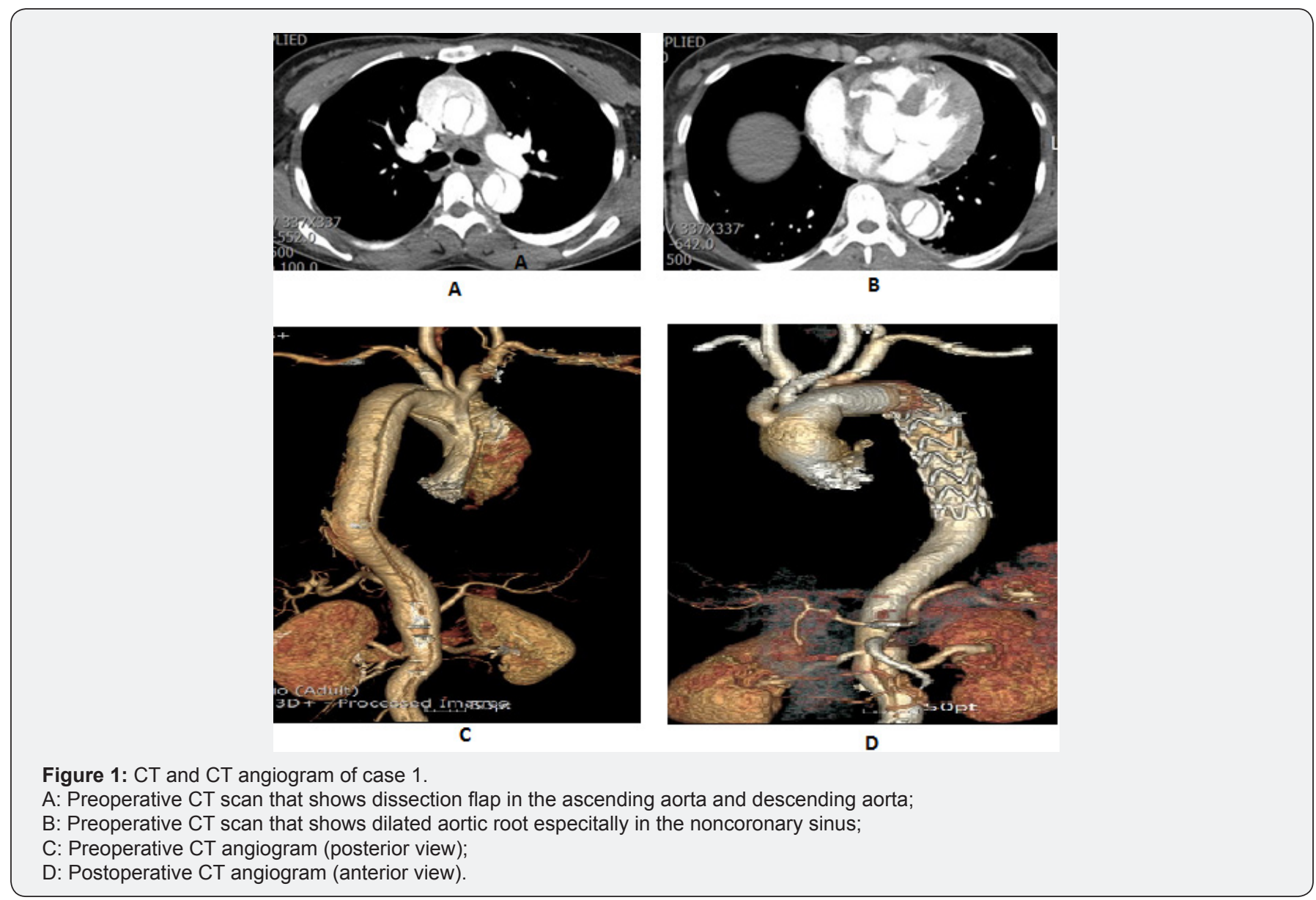

\section{Case 2}

A 39-year-old man was admitted with complaints of a sudden onset back pain. CT scan showed acute type B aortic dissection with anuloaortic ectasia (Figure 2A \& 2B) and the echocardiogram showed severe to moderate aortic regurgetation. The patient showed Marfanoid appearance. We planed an elective total surgical correction for the lesions at once. Most of the operative procedures were performed similar to the first case. During the operation, we found that the aortic root was dilated severly and there was a transverse intimal tear within the aortic root so we concluded that the anuloaortic ectasia was resulted from a focal chronic aortic root dissection. There was a small artery originated from aortic arch between the left carotid artery and the left subclavian artery, that was the left vertebral artery and the artery was connected to the left subclavian artery side by side and than anastomosed to the most distal side branch of aortic graft. The subanular horizontal mattris sutures were made with 14 pledgetted 2-0 Tycrons and the root were replaced with $30 \mathrm{~mm}$ tube graft. The distal aorta was transected between the left carotid artery and the left subclavian artery after division and ligation of the origin of the left subclavian artery. The dissection was started distal to the origin of the left subclavian artery so the $28 \mathrm{mmx} 15 \mathrm{~cm}$ Valiant Captiva stent graft covered from the nondissected normal arch segment to the distal dissected descending aorta. The arch was replaced with $28 \mathrm{~mm}$ four sided arch graft with the same previous maneuver. The total operative time was 6 hours and 18 minutes, and total by pass time was 4 hours and 43 minutes, and the coronary ischemic time was 3 hours and 3 minutes. After the operation the ventilator support period was 16 hours and total ICU stay period was 5 days. After 12 days of the operation the patient discharged without any complications. We checked CT angiogram and Echocardiogram and there were no aortic regurgitation and no abnormality in graft (Figure 2C). 


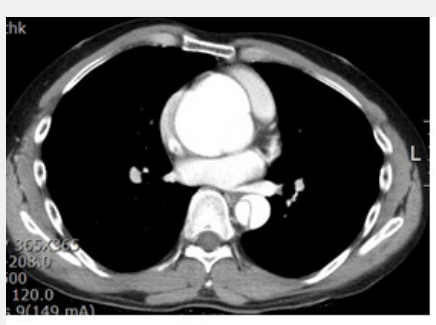

A
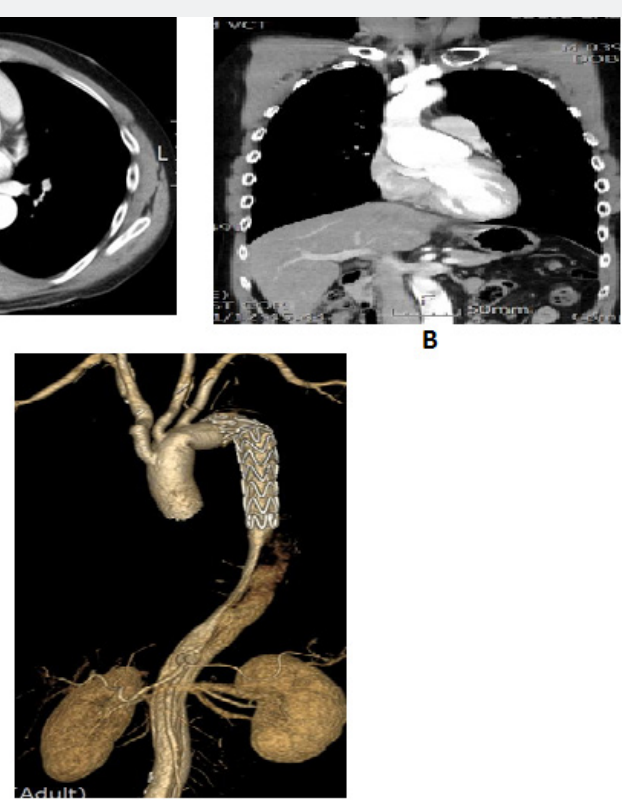

C

Figure 2: CT and CT angiogram of case 2.

A: Preoperative CT scan that shows marked enlargred aortic root and dissection flap in descending aorta;

B: Preoperative CT scan (sagittal view) that shows enlarged aortic root;

C: Postoperative CT angiogram

\section{Discussion}

In most acute aortic dissection, the aortic root procedures are not needed. But when the root dilatation is combined with acute aortic dissection, the supracommissural aortic replacement only will not be the promising long term result and end up redo operations. That will be obvious especially in young Marfan syndrome. Actually, there has been controversy in the root corection of the acute aortic dissection [1]. In acute phase of aortic dissection the main goal of the surgery is life saving. A complex procedure with long operative time will be a risk factor of surgical bleeding and result in surgical mortality in acute dissection situation. The aortic root replacement with composited valved graft had been applied frequently in such pathology but it has disadvantages of lifelong anticoagulation. We already reported our exprience about the root replacement with composited graft [2] and the result in acute aortic dissection was not so satisfactory. David [3] reported first the valve sparing root reimplantation procedure and the procedure has been applied world widely to aortic root aneurysm and ascending aortic aneurysm associated with aortic valve insufficiency. That procedure also has been applied in acute aortic dissection combined with root dilatation especially in young Marfan patients [4]. The long-term outcome of the procedure has been excellent in most reports, and even in acute aortic dissection the root reimplantation procedure showed quite safe and endurable results [5].

The authors have experienced a case of redo Bentall operation due to root pseudoaneurysm after superacommissural aortic replacement in annuloaortic ectasia with acute type A aortic dissecion. So we planned aortic root reimplantation with aortic replacement in aortic dilatation combined acute aortic dissection. The first case was a typical aortic root dilatation combined acute type A aortic dissection. According to our eletrophysiologic study the AV block developed after the operation turned out from His bundle injury, that will need permenant pacemaker insertion in near future even though the patient dosenot complaint any symptoms.

The second case was chronic aortic root dissection which caused the anuloaortic ectasia and aortic regurgetation and acute type B aortic dissection was superimposed. In most acute type B aortic dissection doesnot need surgical correction in their acute phase. But in this case recently developed dyspnea due to pulmonary edema from aortic regurgetation that needed surgical treatment. And the patient was a young Marfan syndrome and needed no remnant aortic tissue that will cause redilatation. So, we planned total correction of chronic aortic root problme and distal acute aortic dissection simultaneously and the result was successful.

\section{References}

1. Tirione ED, Miller DC, Mitchell RS (2003) Acute type A aortic dissection complicated by aortic regurgitation: Composite valve graft versus separate valve graft versus conservative valve repair. J Thorac Cardiovasc Surg 126(6): 1978-1985.

2. Park KJ, Woo JS, Cho GJ, Bang JH, Jeong SS (2010) Clinical study of composite valve graft replacement of the aortic root. Korean J Thorac Cardiovasc Surg 43(3): 260-265. 
3. Tirone ED, Feindel CM (1992) An aortic valve-sparing operation for patients with aortic incompetence and aneurysm of the ascending aorta. J Thorac Cardiovasc Surg 103: 617-621.

4. Thomas PG, Frank L, Nikolaus N, Diana A, Hans Joachim S (2000) Valve preserving operation in acute aortic dissection type A. Ann Thorac Surg 70: 1460-1465.
5. Tirone ED (2012) Aortic valve sparing operations: A review. Korean J Thorac Cardiovasc Surg 45(4): 205-212.
(CC) This work is licensed under Creative

BY DOI: 10.19080/JOCCT.2018.11.555812
Your next submission with Juniper Publishers will reach you the below assets

- Quality Editorial service

- Swift Peer Review

- Reprints availability

- E-prints Service

- Manuscript Podcast for convenient understanding

- Global attainment for your research

- Manuscript accessibility in different formats

( Pdf, E-pub, Full Text, Audio)

- Unceasing customer service

Track the below URL for one-step submission https://juniperpublishers.com/online-submission.php 